\title{
Tasarruf ve Enflasyon İlişkisi: Türkiye İçin Bir Eş-Bütünleşme Analizi
}

\author{
Yüksel Okşakª, , Eda Özenc
}

Özet

Tasarruf ve enflasyonun ülke ekonomilerine etkisi, bu etkinin yönü ve nedenselliğine dair yapılan ampirik çalışmalar her geçen gün artmaktadır. Sıklıkla çalışılan bir konu olmasına karşın; her dönem gösterdiği etkilerin farklılaşması, dinamik bir sitemin içerisinde her dönem farklı makroekonomik değişkenlere farklı sonuçlar doğurabilmesi tasarruf-enflasyon ikilisini hep güncel konular arasında yer almasına neden olmuştur.

$\mathrm{Bu}$ makalenin temel amacı, enflasyonun tasarruf üzerindeki etkisine 1 şık tutmak ve enflasyonun tasarruflar üzerindeki doğrusal olmayan etkilerini araştırmaktır. Dolayısıyla, doğrusal tasarruf modeliyle birlikte, çeşitli ekonometrik yöntemleri kullanarak doğrusal olmayan modelde enflasyon ve tasarruf ilişkisi incelenmektedir. Bu amaç doğrultusunda tasarruf ve enflasyon arasındaki ilişki Türkiye Örneği üzerinde ele alınmıştır. Türkiye üzerinde yapılan analizlerde durağanlık analizi ve akabinde ise nedensellik ilişkisi ele alınmıştır. Elde edilen analiz sonuçlarında tek yönlü nedensellik ilişkisi tespit edilerek sonuç kısmında ayrıntılı bir şekilde ifade edilmiştir.
Anahtar Kelimeler

Tasarruf

Enflasyon

Eş Bütünleşme

Makale Hakkında

Geliş Tarihi: 30.04 .2020

Kabul Tarihi: 05.08.2020

Doi: 10.18026/cbayarsos.730305

\section{The Relationship between Savings and Inflation: An Analysis of Co-Integration for Turkey}

\begin{abstract}
Empirical studies on the effect of savings and inflation on the country's economies, the direction and causality of this effect are increasing day by day. In this study, the relationship between savings and inflation is discussed in the case of Turkey. The stability of the two series studied was investigated by analysis. As a result of the analysis, it was determined that both series are stationary in their first differences. In the later analysis, short and long term relationships were discussed. According to the results obtained, there is a statistically significant relationship between savings and inflation both in the short run and the long run. While the increase in inflation increases the savings in the short term, an increase in inflation decreases the savings in the long term. To determine the causality relationship between the series, the Granger causality test was applied with Toda Yamamoto approach. As a result, it has been determined that there is a one-way causality relationship with $10 \%$ significance level from saving to inflation.
\end{abstract}

Keywords
Savings
Inflation
Cointegration

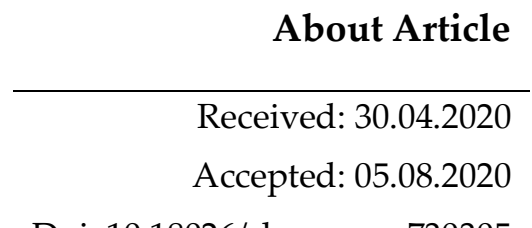

Doi: 10.18026/cbayarsos.730305

a İletişim Yazarı: yukseloksak@uludag.edu.tr

b Dr. Öğretim Üyesi, Bursa Uludağ Üniversitesi İnegöl İşletme Fakültesi, Uluslararası İşletmecilik ve Ticaret -ORCID: 0000-0001-8794-4597

c Dr. Öğretim Üyesi, Bilecik Şeyh Edebali Üniversitesi, İ.İ.B.F. İktisat Bölümü ve ORCID: 0000-0002-0818-1040 


\section{Giriş}

İstikrarlı bir ekonomik büyümenin sağlanabilmesi için fiyat istikrarı en önemli parametrelerden biri olarak karşımıza çıkmaktadır. Bir ekonomide fiyatlar genel düzeyinin dar bir bantta iniş çıkış yapıyor olması bahse konu istikrarın sağlanması için gerekmektedir. Enflasyon, bir ekonomide belirli bir süre boyunca mal ve hizmetlerin genel fiyatlarında sürekli bir artış şeklinde tanımlanmaktadır. Bu artışlar bir dönem önce satın alınan aynı mal veya hizmet için daha fazla para ödenmesine neden olmaktadır. Bir ülke ekonomisinin ne düzeyde enflasyon içinde olduğunu tespit etmek bir kenara, şimdiye kadar bu enflasyonun sebeplerinin neler olduğuna ilişkin bir fikir birliği olduğunu söylemek güçtür. Literatürde Keynesyen ekol tarafından geliştirilen Talep-Çekişli enflasyon teorisi enflasyonu mal ve hizmetlere olan talebin artışına dayandırmaktadır. Teori talepteki ani artışların arz cephesinde aynı hızla sağlanamadığına dikkat çekmektedir. Bu nedenle de arz sınırlı kalmakta ve bahse konu yüksek talep fiyat artışlarına neden olmaktadır. Bir başka teorik yaklaşım ise maliyet itişli enflasyondur. Bu ise ürün/hizmet üretiminde kullanılan girdi (işgücü, yarı mamül, ham madde gibi) fiyatlarındaki artışlar nedeniyle bu ürün ve hizmet fiyatlarının belirli oranda karı korumak isteyen arz cephesi tarafından arttırıldığına dikkat çekmektedir. Enflasyonun nedenlerini açıklamak için kullanılan diğer bir teori Monetarist yaklaşım olarak literatürdeki yerini almaktadır. Bu teoriye göre enflasyon para arzındaki artışın bir sonucu olarak oluşmaktadır.

Enflasyon kavramı geçmişten günümüze birçok iktisatçının ve iktisat okulunun da gündemini meşgul etmiştir. Kynesyen iktisat ekolü fiyatların aşağı yönlü rijit olduğunu, enflasyonun yüksek seyrettiği ülkelerde karlılığın emekten (işgücünden) sermayeye (girişimciye) doğru yöneldiğini ve bu şekilde ekonomik büyümeyi arttıracağına vurgu yapmaktadır. Monetarist yaklaşımı benimseyen iktisatçılar ise enflasyonu genel olarak bir sorun olarak görmekle birlikte hiperenflasyon oluşmadıkça enflasyonun genişletici para politikası ile giderilebileceğine dikkat çekmektedirler. Klasik iktisat okulu, uzun dönemde ücret ve fiyatlar genel düzeyinin esnekliği sebebiyle enflasyonun uzun dönemde dengede olacağını fakat kısa dönemde ise artacağını belirtmektedirler. Servet'e $(2018$, s. 57) göre ilk dönem çalışmalarda enflasyonun ve/veya enflasyon belirsizliğinin hane halkı tasarruf oranlarını arttırdığını, sonraları enflasyonun tasarruf birikimi üzerinde azaltıcı etkisinin olduğunu hatta uzun dönemli bir etkisinin olmadığını ön plana çıkarmıştır.

$\mathrm{Bu}$ teoriler zaman içerisinde geliştirilmiş ve hemen hepsi ampirik olarak test edilmiştir. Fakat yapılan bu testler enflasyonun nedenlerine dair kesin olmayan bulgular ortaya koymaktadır. Yapılan bazı çalışmalar para arzı ve faiz oranının enflasyondaki ana itici gücü olduğunu bildirirken, diğer çalışmalar enflasyonun arkasındaki temel nedenlerin döviz kuru, mal ve hizmet ithalatı olduğuna dair bulguları literatüre kazandırmaktadır. Son dönemde dışa açıklığın artması ve içsel büyüme teorilerin baskınlığı, enflasyonun ulusal tasarruflara etkisi konusundaki teorik ve ampirik çalışmaların azalmasını daha çok enflasyonun ekonomik büyüme üzerindeki etkisine odaklanılmasını sağlamıştır.

Tasarruf iktisat biliminde tüketim ve tasarruftan gelirin bir bölümü yani gelirin harcanmayan kısmı olarak tanımlanmaktadır. İlk dönem iktisatçılardan başlamak kaydı ile günümüze kadar birçok bilim insanı tasarrufu ve tasarruf miktarını açıklamaya çalışan çalışmalar geliştirmektedirler. Gelirin ne kadarlık bir kısmının harcanması gerektiğini (Ramsey, 1928, s. 544), harcanabilir gelir arttıkça tüketimin de artacağını (Kynes, 1936, s. 90-112), tasarrufun o günkü gelire değil de yaşam boyu elde edilen gelir bağlı olduğunu (Modigliani ve Brumberg, 
1954), harcanabilir gelir artmadan da tüketimin artabileceğini yani tasarrufların azabileceğini (Pigou, 1943, s. 345), harcamaların sürekli gelir ile ilişkili olduğunu (Friedman, 1957, s. 21) öne süren bir çok çalışma yapılmıştır. Son dönemde ise; yaşam boyu belirsizlikle yaşam döngüsünü ve başkalarını da düşünen (Kuehwein, 1993, s. 38-47) tasarruf teorileri, mikro teoriler çerçevesinde ele alınan hanehalkı tasarrufları (Browning ve Lusardi, 1996, s. 1797), kurumsal ve diğer geleneksel olmayan tasarruf teorileri (Green, 1991, s.93), alternatif tasarruf teorileri (Bremms, 1979, s. 161) geliştirilmektedir.

Enflasyon, tasarruf, döviz kurları vb. bir dizi makroekonomik faktör ülkelerdeki reel ekonomik büyümeyi büyük ölçüde etkilemektedir. Reel ekonomik büyümenin hızlanmasında tasarruflar önemli rol oynamaktadır. Neoklasik büyüme modelleri, kısa vadede tasarruf oranındaki artışın, esas olarak sermayenin verimliliği üzerindeki olumsuz etkisinden dolayı büyüme oranı üzerinde olumlu bir etkiye sahip olduğunu öngörmektedir. Tasarruf oranının uzun vadede ekonomik büyümeyi olumlu etkilediği çok sayıda ampirik çalışma da bulunmaktadır.

Enflasyon gelişmekte olan ülkelerde daha derin bir problem olarak karşımıza çıkmaktadır. Genel olarak yüksek enflasyon düzeyinde sahip olan gelişmekte olan ülkelerde gelirin büyük bir bölümünün tüketime ayrılmasını daha düşük bir tasarruf miktarı ile içsel yatırımların karşılanamaması durumu meydana gelmektedir. Böyle bir durum ise tasarrufun yurtdışından ithal edilmesini beraberinde getirmektedir. Tasarruf açığını kapatmak adına da özellikle sıcak para çekme rekabeti ile karşı karşıya kalınmaktadır. Düşük gelir düzeyine sahip ülkeler ve bireyler yüksek tasarruf imkanını da zora koşmaktadır. Bu nedenle enflasyon, tasarruf ilişkisi literatürde sıkça ele alınan konular arasında yer almaktadır.

Tasarruf ile enflasyon ilişkisi doğrudan ekonomik büyüme, sermaye birikimi ve yatırımlarla ilişkilidir. Bu manada genel anlamda ulusal tasarruflar iktisat literatüründe önemi haiz merkezi bir konudur. Genel anlamda ulusal tasarruflar, hane halkının kullanılabilir gelirinden yaptıkları özel tasarrufların ve kamu gelirinin harcanmayan kısmından teşkil kamu tasarruflarının bileşiminden oluşmaktadır. Temel iktisat metinlerinde tasarruf ekonomik büyümenin ana kaynakları arasında gösterilmektedir. Ancak modern ekonomik büyüme teorileri ulusal tasarruf olgusundan yeterince bahsetmemektedir. Buna rağmen bu çalışmanın ana içeriklerinden birisi olan tasarruflar ekonomik büyümenin en asli unsurlarından bir tanesidir.

Yine de ulusal tasarrufların her zaman bir kaynak olarak sermaye birikimi ve ekonomik büyümeyi artıracağı düşüncesi yanlış olacaktır. Zira tasarrufların sermaye birikimi ve buna bağlı olarak ekonomik büyümeyi artırmasını engelleyecek bir dizi faktör bulunmaktadır. Bunlardan en önemlileri; gelir ve fiyatlardaki belirsizlik, enflasyon, yüksek faiz vb. unsurlardır. Juster ve Wachel (1972, s. 765) Brookings'in ekonomik harcamalar ve tasarruf kararlarında beklenti değişkenlerinin rolünü incelemek bağlamında fiyat enflasyonu ile tüketici tasarrufu arasındaki ilişki hakkında bulgular sunmaktadırlar. Çalışma öncelikli olarak dayanıklı tüketim harcamaları modellerine odaklanmış ve bu modellerde açıça beklenen değişkenlerin yararlıı̆̆ına dair kanıt sunmaktadır. Ayrıca, dayanıklı tüketim harcamaları kararlarıyla ilişkili basit bir tasarruf fonksiyonunu ele alan çalışma tamamen tasarruf üzerine odaklanmaktadır.

Dolayısıyla bu çalışmada Türkiye gibi gelişmekte olan ekonomilerdeki en önemli sorunlardan biri olan enflasyonun tasarruf ile ilişkisi ele alınmaktadır. Mevcut çalışmalara ve güncel 
iktisadi yaklaşımlara göre enflasyon ekonomik büyüme üzerinde olumsuz bir etkiye sahiptir. Ancak enflasyonun uzun ve kısa vadeli etkileri üzerine yapılan çalışmalarda bir uzlaşım noktası bulunmamaktadır. Örneğin Keynesçi yaklaşıma göre enflasyon ekonomik büyüme oranında olumlu bir etkiye sahip olduğu görüşü kabul görürken, günümüzde enflasyonun ekonomik büyüme kontekstinde negatif bir etki yarattığ 1 kabul gören görüşler arasındadır (Topçu, 2017, s.181). Diğer bir başka yaklaşım ise gelişmekte olan ülkelerde piyasanın yeterince gelişmemiş olmasının bir sonucu olarak enflasyonun tasarrufları uzun vadede düşüreceğini ifade etmektedir (Leff ve Sato, 1988).

Enflasyon ile tasarruf arasındaki ilişki konusunda yapılan çalışmalarda da benzeri bir durum söz konusudur. Yapılan birçok çalışmaya göre enflasyonda meydana gelen artış bireylerin tüketimi azaltmasına ve dolayısıyla tasarrufun artacağına işaret etmektedir. Bu tarz çalışmalarda elde edilen ampirik verilere göre enflasyon sebebiyle fiyatlarda meydana gelen artış zorunlu tasarrufu artırmaktadır. Bunun yanında yine birçok çalışma enflasyon artışı ve tasarruf arasında negatif bir ilişki kurmaktadır. Buna göre enflasyon oranında meydana gelen artışlar kişileri tasarruflarının zamanla değerini yitireceği endişesiyle değerini yitirmeyecek ve hatta zamanla değer kazanacak alanlarda yatırıma teşvik etmektedir. Elinizdeki çalışma ise her iki görüşten ve bu alanda yapılan ampirik ve teorik çalışmalardan yola çıkarak enflasyonda meydana gelen artışın kısa vadede tasarrufu teşvik edeceğini, fakat uzun vadede yaratacağı belirsizlik sebebiyle tasarrufları azaltacağı fikrini ortaya koymaktadır.

Enflasyon-tasarruf ilişkisine yönelik yapılan ilk dönem çalışmalar enflasyonun tasarrufu artırıcı etkisine vurgu yaparken, sonraki dönemde yapılan çalışmalar tasarrufu azalttığ yönünde bir etkiye vurgu yapmaktadır. Özellikle içinde bulunduğumuz dönemde, enflasyonun özel ve kamusal tasarruflara olan etkisi Türkiye kontekstinde bu konuyu önemli kılmaktadır. Bilhassa Türkiye'nin yaşadığı ve yaşamakta olduğu yüksek enflasyon tecrübesi, enflasyon ile tasarruflar arasındaki ilişkinin yeniden tartışılmasını gerekli kılmaktadır.

Bu çalışma tasarruf ile enflasyon arasındaki ilişkiyi geniş bir yelpazede daha güncel olarak ele almaktır. 1974-2017 yıllarına ait veriler ile Türkiye üzerine bir ampirik analiz yapılmaktadır. Yapılan analizde nedensellik ve eş bütünleşme testleri ile tasarruf ve enflasyon arasındaki kısa ve uzun dönemli ilişkiler araştırılmaktadır.

\section{Literatürde Enflasyon ve Tasarruf İlişkisi}

Enflasyonun anlaşılması, nedenlerinin ne olduğunu, yani genel fiyat seviyesindeki artışın arkasında hangi faktörlerin olduğunu anlamak demektir. Enflasyon ekonomik büyüme üzerindeki etkisi nedeniyle, ekonomik araştırmalar arasında henüz bir fikir birliğine varılamamış bir çalışma konusudur.

Amaefule ve Maku (2019, s. 314)1985'ten 2018 yılına kadar 34 yıllık bir dönem için Nijerya'da ülke içi tasarruflar, döviz kuru, enflasyon ve imalat sektörüne ait verileri incelemektedir. Veriler, ulusal tasarrufların, döviz kurunun ve enflasyonun imalat sektörü üzerindeki etkisini incelemek üzere ARDL yöntemi kullanılarak analiz edilmiştir. Ulusal tasarrufların imalat sektörü üretimi üzerinde kısa vadeli bir etkisi olmadığını, imalat sektörü üzerindeki uzun vadeyi de etkilediğini ortaya koymaktadırlar. Enflasyonun imalat sanayi üretimi ile olumsuz ilişkisini tespit edilmektedir. Ampirik bulgular, ulusal tasarrufların imalat sektöründeki yatırımı hafifletmek için yeterli seviyeye sahip olmadığını göstermektedir. Bu nedenle, çalışma; hükümetin imalat sektörüne doğrudan yabancı yatırımı teşvik edecek politikalar geliştirmesi gerektiğini önermektedir. 
Ferreira (2017, s. 2) 1995 ve 2014 yılları arasında yıllık olarak gözlemlenen 42 ülkeden oluşan bir panel aracılığıyla enflasyonun tasarruflar üzerindeki etkisini araştırmaktadır. Panel eşik modeli yaklaşımı takip ettiği tezinde, bulgular, enflasyonun, özellikle düşük enflasyon seviyelerinde, brüt tasarruflar üzerinde olumlu bir etkiye sahip olduğunu göstermektedir.

Tüketicilerin enflasyon beklentileri ile harcama ve tasarruf davranışları arasındaki ilişkiyi ele aldıkları çalışmalarında Premik ve Stanisławska (2017, s. 3), satın alma ve tasarruf tutumlarını birlikte incelemektedir. Büyük bir mikro veri seti kullanan analiz, enflasyon beklentilerinin özellikle çok iyi bir finansal durumla karakterize edilen tüketici grubunda tasarruf tutumlarını olumsuz etkilediğini göstermektedir. Ayrıca, küresel mali krizden bu yana enflasyon beklentilerinin rolünün arttığına değinmektedirler. Satın alma tutumlarına ilişkin sonuçları şaşırtıcı bulan Premik ve Stanisławska, enflasyon beklentileriyle ilgili çok zayıf da olsa olumsuz bir bağlantı olduğunu göstermektedirler.

Tasarruf, enflasyon ve ekonomik büyüme arasındaki karşılıklı ilişki, ekonomik performansın senkronize değerlendirmesinde önemli bir konjonktürdür. Richardson ve Innocent (2015, s. 180) tasarruf, enflasyon ve büyüme kavramlarını birlikte ele alan çalışmalarında enflasyonun ve reel ilginin ekonomik büyüme ile olumsuz ilişkili olduğunu, döviz kurunun ekonomik büyüme üzerinde olumlu etkisi olduğunu ortaya koymuşlardır. Çalışmada ekonomik büyüme, işsizlik ve reel faiz de enflasyonu olumsuz etkilemiş, dolaylı vergiler ise enflasyonu olumlu etkilemiştir. Ayrıca ekonomik büyümenin; döviz kuru ve doğrudan yabancı yatırımlar tasarruf sağlarken, amortisman oranı tasarrufları tehlikeye atmaktadır. Çalışmada, enflasyon düzeyinin yüzde 8'lik eşik seviyesinin Nijerya büyümesi ile uyumlu olduğu tespit edilmiş ve bu noktanın ötesinde enflasyonun büyümeyi tehlikeye atacağına dikkat çekilmektedir. Blinov'a (2015, s. 1) göre tasarruf ekonomi için büyük bir nimettir. Bununla birlikte, tasarrufların ekonomik otoriteler tarafından yönetilmesinde yapılan hatalar, her şeyi altüst edebilir ve daha sonra tasarruflar enflasyon gibi diğer birçok ekonomik sıkıntıya neden olabilir.

Patra, v.d. (2015, s. 75) 1981-2011 dönemi için panel veri yaklaşımı ile Asya'daki tasarrufbüyüme-enflasyon bağını incelemektedir. Tasarruf ile ekonomik büyüme arasındaki karşılıklı ilişkinin, tasarruftan ekonomik büyümeye doğru kayda değer ve tek yönlü olduğu ortaya konulmaktadır. Ekonomik büyüme enflasyonu olumsuz ve önemli ölçüde etkilerken enflasyon tasarrufları olumlu ve önemli ölçüde etkilemektedir. Tasarruf, ticaret açıklığı ve nüfus artışı gibi değişkenlerin ekonomik büyümede önemli belirleyiciler olduğu tespit edilmektedir. GSYH dışında reel faiz oranı, enflasyon, bağımlılık oranı ve okuryazarlık oranı gibi değişkenlerin tasarruf oranının önemli belirleyicileri olduğu bulunmuştur. Benzer şekilde, para arzı, büyüme hızı ve reel faiz oranı gibi değişkenler enflasyonun ana belirleyicileri olarak bulunmuştur. Kişi başına reel GSYİH büyüme oranını açıklamak için ülkeye özgü herhangi bir etki bulunamamıştır.

Türkiye'de tasarruf, enflasyon ve ekonomik büyüme arasındaki kısa ve uzun vadeli ilişkiyi ARDL yaklaşımı ile inceleyen araştıran Tuğcu ve Çoban (2014, s. 81), tasarrufun, enflasyonun ve ekonomik büyümenin bütünleştiğini ortaya koymaktadırlar. Enflasyonun ya da ekonomik büyümenin Türkiye'deki tasarruf üzerinde olumlu etki meydana getirdiğine değinmektedirler. Tuğcu ve Çoban'a göre kısa vadede enflasyon ve tasarruflar ile uzun vadede faiz oranları ve tasarruflar arasında istatistiksel olarak anlamlı bir ilişki olmadığını ortaya koymaktadırlar. 
Ilyas v.d. (2014, s. 125) çalışmalarında ekonomik büyüme, tasarruf ve enflasyon arasındaki ilişkiyi araştırmak ve Pakistan ekonomisi için enflasyon eşik seviyesini tahmin etmeyi amaçlamaktadırlar. 1973-2010 yılları arasında yıllık zaman serileri verileri kullandıkları araştırmada enflasyon, ekonomik büyüme ve tasarruf endojen değişkenken, işsizlik, doğrudan yabancı yatırım, amortisman oranı, reel faiz oranı, toplam borç servisi, dolaylı vergiler, bağımlılık oranı ve toplam yatırım dışsal değişkenlerdir. Sonuçlar enflasyonun ve reel faiz oranının ekonomik büyümeyi olumsuz ve önemli ölçüde etkilediğini, amortisman oranının ise ekonomik büyümeyi olumlu etkilediğini göstermiştir. Ekonomik büyüme, işsizlik ve reel faiz oranı enflasyon oranını olumsuz yönde etkilerken, dolaylı vergilerin enflasyon üzerinde olumlu etkisi olmuştur. Sonuçlar aynı zamanda ekonomik büyüme, bağımlılık oranı (çalışma çağındaki nüfusun yüzdesi) ve doğrudan yabancı yatırımın bir ülkenin tasarruflarını arttırmak için faydalı olduğunu, amortisman oranının tasarruf için zararlı olduğunu göstermiştir. Bulgularda enflasyon ile tasarruflar arasında anlamlı bir ilişki olmadığı da gözlemlenmiştir.

Cheng ve Li (2014, s. 16-17) enflasyon oranının ulusal tasarruflar (GSMG yüzdesi) üzerinde önemli bir olumlu etkiye sahip olduğunu göstermektedir. Bu sonuç, enflasyon oranı ile ulusal tasarruflar arasındaki ilişki üzerine ekonomik ilkeleri göz önüne alırken bekledikleri sonuçtur. Çalışma ayrıca, fazla gelirin daha fazla tasarruf sağlayacağına; yüksek işsizlik oranının tasarruf için parası olan insanların sayısını azaltacağına ve dolayısıyla tasarrufları azaltacağına dikkat çekilmektedir.

Igbatayo ve Agbada (2012, s. 447) Nijerya'da enflasyon, tasarruf ve çıtı arasındaki ilişkiyi Vektör Otoregresyon (VAR) yaklaşımı kullanılarak araştırmaktadırlar. Bulguları arttırmak ve sonuçların sağlamlığını ortaya koymak için VAR analizi boyunca Sıradan En Küçük Kareler ve Granger nedensellik testleri de uygulamaktadırlar. Bulgular enflasyonun çıktıyı azaltma eğilimini gösterirken, tasarrufların çıktıyı gerçekten uyardığını göstermektedir. Enflasyondaki değişikliklerin analiz boyunca çıktı büyümesini veya Nijerya'daki tasarrufları uyarmadığını veya yeterince tepki vermediğini göstermektedir. Özetle ampirik kantlar, Nijerya ekonomisinde enflasyon, özel tasarruf ve çıktı (GSYİH) arasındaki davranışlar veya nedensonuç ilişkisi hakkında bazı yararlı ipuçları sağlamaktadır.

Mansoorian, v.d. (2010, s. 365) enflasyon oranındaki artışın, istikrarlı yaşam standartlarında bir düşüş gerektirdiğine değinmektedirler. Analizlerinde yüksek enflasyon oranına sahip sekiz ülkeden, enflasyondaki artıştan sonra çıktı ve yatırımın düştüğünü ve net yabancı varlık pozisyonunun zamanla kötüleştiğini gösteren kanıtlar sunmaktadırlar.

Heer (2009, s. 615) enflasyonun tasarruflar üzerindeki etkileri üzerine yapılan çalışmaların teorik kanıtlarının karışık olduğunu belirtmektedir. Daha evvel yapılan çalışmalardan birinin genel bir denge çerçevesi üzerinde çalıştığına, paranın istikrarlı durumda süper nötr olduğuna dikkat çekmektedir.

Güneydoğu ve güney Asya için ekonomik büyüme, tasarruf oranı ve enflasyon arasındaki ilişkiyi eş zamanlı bir denklem çerçevesinde panel verileriyle iki aşamalı olarak inceleyen Chaturvedi v.d. (2008, s. 2); tasarruf oranı ile büyüme arasındaki ilişkinin iki yönlü ve pozitif olduğu ortaya koymaktadırlar. Enflasyonun büyüme üzerinde oldukça önemli bir olumsuz etkisi, ancak tasarruf oranı üzerinde olumlu bir etkisi olduğuna işaret etmektedirler. Chaturvedi v.d. enflasyonun büyümeden, tasarruf oranının da faiz oranından etkilenmediğine dikkat çekerek, Asya'daki ülkelerin uygulayacakları politikalar ve stratejiler 
için çok önemlidir bulgular olduğunu vurgulamaktadırlar. Agarwal, J. ve Agarwal (2005, s. 421) ise finansal gelişmeyi, bir ekonomide bir araya getirilen enflasyon ve tasarrufların bir fonksiyonu olarak modellemeye çalışmaktadır.

Motley de (1998, s. 16) enflasyon oranının yükselmesi ve bu yükselmenin yaratacağı belirsizlik durumunun GSYHİ içerisindeki sermayeyi azaltacağından tasarruf kararını olumsuz yönde etkileyeceğine dikkat çekmektedir. İnsanlar enflasyonun belirsiz ve hayli yüksek olduğu durumlarda sermaye olarak elde tutulan para sürekli değer kaybedeceğinden uzun vadede ellerindeki tasarruflarını değer kaybını önlemek adına mal, arsa, gayrimenkul gibi reel alanlara yatırmaktadır (Barro, 1996, s. 1). Bruno ve Easterly (1995, s. 9)'nin yaptığı çalışmaya göre enflasyon alım gücünde meydana getirdiği zayıflamaya bağlı olarak zorunlu tasarrufu artırmaktadır. Yine enflasyon ile tasarruf arasındaki ilişkiye dair uzun vadeli değerlendirmelerde de enflasyon artışının faiz getirilerini azalttığı ve buna bağlı olarak tasarrufları da olumsuz yönde etkilediği sonucuna ulaşılmıştır. Den Haan (1990)'da uzun vadede enflasyonun tasarrufları azaltacağı yönünde ampirik veriler toplamıştır.

Enflasyon olgusunun tasarruflar üzerinde nasıl bir etki uyandıracağ meydana gelen artışa gösterdikleri reaksiyon ile yakından ilgilidir. Bireyler tasarruflarını ne kadar finansal enstrümanlardan tüketim ürün ve/veya hizmetlerine kaydırırsa tüketilen gelir miktarı artacak dolayısıyla tasarruf edilen miktar ise azalacaktır. Servet sahipleri ise enflasyonist ortamlarda servetlerini korumak ister ve tasarruflarını arttırma yoluna giderler. Kurumsal altyapısı güçlü olmayan ekonomilerde enflasyonist ortamlar tasarrufların azalmasına neden olacaktır. Enflasyonun tasarruflar üzerindeki etkisiyle ilgilenen modellemelerin büyük bir kısmında enflasyonun tasarrufları olumsuz etkilediğine dair bulgular mevcuttur. Aşırı yüksek enflasyon dönemlerinde para tutmanın maliyeti yükseldiği için böyle dönemlerde tasarruftan ziyade tüketim artışları fayda sağlayıcı olabilmektedir. Paranın yansızlığı teorisi ise enflasyonun uzun vadede tasarruflar üzerinde etkili olmayacağına vurgu yapmaktadır.

Enflasyonun tasarruflar üzerindeki dolaylı etkisi, bilim insanlarını olumsuz bir katkı görüşü ile olumlu bir etkiyi destekleyenler arasında pay etmektedir. Ancak benzersiz ve kesin bir cevap ortaya konamamaktadır. Ayrıca, elastik bir işgücü arzı göz önüne alındığında, tasarruf oranı enflasyonla artabilir veya azalabilir.

Bonu (1995, s. 25) Botsvana Hükümeti'nin tasarruf politikalarını konu edindiği çalışmasında, vergilendirme politikasının henehalkı inisiyatifine bırakılan kısmını eleştirmektedir. $\mathrm{Bu}$ yöntemde hanehalkının tasarruflarını ekonomik kalkınma için yönlendirmeyi göze alamayacağına ve böylece gelirlerini tüketim faaliyetlerine yönlendireceğine dikkat çekmektedir. Belirlenen eşit değerinin otomatik düzeltme enflasyonu ile bağlantılı olması, düşük gelir grubuna yönelik bir vergi muafiyetinin ilan edilmesi ve kimlerin tasarruflarını tüketim faaliyetlerinden, kimlerin kalkınma projelerinden yana kullandığını değerlendirmek için vergi tavizlerinin uzatılmasını önermektedir. Thompson ve Ottosen'in (1993, s. 45) çalışması, uzun vadeli enflasyon beklentilerindeki bu değişimin kişisel tasarruf oranındaki düşüşün önemli bir nedeni olduğunu ve kredi standartları üzerinde de önemli etkileri olduğunu savunmaktadır. Deneyimlerin, her kriz geçtiğinde enflasyonun hızla sona ereceğini öğrettiğine dikkat çekmekte ve enflasyonun daha da kötüleşebilecek sürekli bir sorun olarak görüleceğini vurgulamaktadırlar. 
Zenginliğin esas olarak parasal varlıklarda depolandığı eski Sovyetler Birliği gibi ülkelerde, para-gelir davranışını, istenmeyen para dengesi büyümesinin zayıf bir göstergesi olduğunu vurgulayan Cottarelli ve Blejer (1992, s. 256); bu ülkelerdeki parasal çıkıntıya (Monetary Overhang) dikkat çekmektedirler. Bu çıkıntının tüketim ve tasarruf kararlarının ampirik bir analizini gerektirdiğine değinmektedirler.

Koskela ve Virén (1992, s. 215) enflasyon, sermaye piyasaları ve İskandinav ülkeleri hanehalkının tasarruflarını incelemiştir. Koskela ve Virén (1982, s. 483) bir başka çalışmalarında ise Finlandiya'da enflasyon, sıkı para ve hanehalkı tasarruf davranışını analiz etmişlerdir. Aynı ikili bir başka çalışmada beklenmeyen enflasyonun tasarruf oranını olumlu etkilediği vurgulamaktadır (Koskela ve Virén, 1984, s. 379).

Hızlanan enflasyon ortamında hane halklarının "işlem yapılabilir tasarruflarını" yeniden tahsis etmelerine nasıl yönlendirdiğini açıkladıkları çalışmasında Bodie (1989, s. 193) 1962 ve 1970 Tüketici Finansmanı Anketlerinden alınan kesit verileri, tasarruftan beklenen getiri oranlarını tahmin etmek için kullanmaktadır. Çalışma, hızlanan enflasyonun mevduat faiz oranları üzerindeki kapsamlı tavanların varlı̆̆ında farklı hane halklarının tasarruf teşviklerini değiştirdiğini göstermektedir. Buradaki etki, küçük tasarrufları maddi duran varlıklara (özellikle gayrimenkul) yapılan kaldıraçlı yatırımlara ve büyük tasarrufları mevduat ve menkul kıymet sertifikalarına yöneltmektir. Dezavantajlı krediye erişimi olan küçük koruyucular basitçe mağdur olmaktadır.

Değişen tüketici fiyatlarının ve sermaye kazanç ve kayıplarının İngiltere' de toplam tasarruflar üzerindeki etkilerini ampirik olarak inceledikleri çalışmalarında Pesaran ve Evans (1984, s. 237), toplam gerçek tüketimi mevcut gerçek harcanabilir gelire, sermaye kazanç ve kayıplarına ve ilk varlıkların cari gerçek değerine ilişkilendiren basit bir model ortaya koymaktadırlar. Ortaya koydukları bu model geleneksel yaşam döngüsü teorisi ile uyumludur. Deaton'a (1983, s. 125) göre İngiliz verileri, diğer batı ülkelerinin verileri gibi, 1970'lerin çoğu için görülmemiş derecede yüksek tasarruf oranları göstermektedir. Varlık erozyonunun negatif gelir olarak ele alınmasının bu tabloyu değiştirdiği açık olmakla birlikte, tüketim ile reel gelir arasında herhangi bir basit ilişkiyi düzeltmemektedir. Teorik olarak, tüketimi belirleyen gelir değil servettir ve çalışma, standart yaşam döngüsü modelinin beklenmedik enflasyonun tasarruf oranı üzerinde olumlu bir etki öngördüğünü göstermektedir. Dolayısıyla, Deaton'ın analizi, gerçek likit varlıkların geleneksel tüketim fonksiyonlarına dahil edilmesini desteklememektedir.

Davidson ve MacKinnon (1983, s. 731) Kanada ve ABD'de enflasyon oranları ile tasarruf oranları arasında gözlenen olumlu ilişkinin açıklamasını incelemektedirler. Çalışmada birkaç model, her iki ülkeden üçer aylık zaman serisi verileri kullanılarak tahmin edilmiş ve bunların en iyileri çeşitli testlere tabi tutulmuştur. Gözlemlenen ilişkinin başlıca nedeni, enflasyon zamanlarında ölçülen gelir ve ölçülen tasarrufların gerçek ve algılanan miktarları aşmasıdır. Burkley (1981, s. 124) enflasyon artış hızı ile kişisel tasarruf seviyesi arasında gözlenen pozitif korelasyon için teorik bir altyapı sunmaktadır.

Ungern-Sternberg (1981， s. 961-962) gerçek geliri (bir anlamda tasarrufu) ölçmek için düzeltilmiş bir gelir ölçüsü kullanılabileceğini, düzeltilmiş bu gelir ölçüsü, düzeltme teriminin katsayısı regresyonda endojen olarak belirlenecek şekilde tahmin edilecek tüketim fonksiyonuna dahil edilebileceğini belirtmektedir. Ortaya çıkan regresyonların istatistiksel özellikleri, teorinin reddine veya geçici olarak kabul edilmesine yol açan deliller ortaya 
koymaktadır. Bu hipotezine göre Almanya, İngiltere ve ABD'yi analiz eden Ungern-Sternberg; her üç ülke için de kanıtların hipoteze biraz destek verdiğini fakat ABD sonuçlarının tatmin edici olmaktan çok uzak olduğunu ortaya koymaktadır.

Literatürde genel olarak enflasyon ve tasarruf ilişkisi kontekstinde üzerinde uzlaşılmış bir fikir birliği mevcut değildir. Literatürde ikinci dünya savaşı sonrası dönemde yapılan ilk çalışmalara göre (Campbell ve Lovati, 1979, s. 3) enflasyon ve tasarruf arasında doğru orantılı bir ilişki vardır. Buna göre enflasyonun yükselişi tasarrufu artırmaktadır. Bunu destekler veriler Neo klasik büyüme teorisi çerçevesinde Enflasyon ve tasarruf arasındaki doğrusal ilişkiye yönelik bir başka yaklaşıma göre enflasyon artışının tasarrufu artırması ekonomik belirsizlikle ilişkilendirilmektedir. Buna göre, enflasyon artışının gelirlerin ve fiyatların belirlenmesinde yol açtı̆̆ 1 ekonomik tahmin edilemezlik durumu tasarruflarda artışa sebep olmaktadir (Wachtel, 1977, s. 561-562).

Thirlwall (1974, s. 154) kesit verileri kullanılarak, enflasyonun ılımlı olduğu sürece tasarruf oranının iç enflasyon oranıyla pozitif ilişkili, ancak enflasyon aşırı ise negatif ilişkili olduğu hipotezini geliştirmekte ve test etmektedir. Enflasyon için optimum oranlar elde edilebilir, ancak birçok örnekteki nokta tahminleri sıfırdan önemli ölçüde farklı değildir. Thirlwall'un geliştirdiği model, yabancı sermaye girişlerinin enflasyon-tasarruf ilişkisi üzerindeki çarpık etkilerini yakalamaya ve enflasyon hipotezini yaşam döngüsü hipotezi ve Keynesyen mutlak gelir hipotezi gibi diğer geleneksel hipotezlerden ayırmaya çalışmaktadır. Thirlwall tarafından analiz edilen bir enflasyon, dağılım ve tasarruf modeli değerlendirdikleri çalışmalarında Woodfield ve McDonald (1978, s. 357) alternatif tahminler sunmakta ve genel olarak yeniden dağıtım yoluyla tasarrufları artırmak için çok büyük enflasyon değişikliklerinin gerekli olduğuna vurgu yapmaktadırlar.

Mundel (1963) ve Tobin (1965)'in çalışmalarında da karşımıza çıkmaktadır. İktisat literatüründe Mundel-Tobin etkisi olarak adlandırılan bu ekonomik yaklaşıma göre enflasyon artışı tasarrufu artırmaktadır.

Literatür de görüldüğü üzere çoğunlukla tasarruf- enflasyon ikilisi birçok makroekonomik değişken kullanılarak ekonometrik modeller ile incelenmiştir. Sıklıkla kullanılan makro ekonomik değişkenin ekonomik büyüme olduğu görülmektedir. Bu çalışmada ise literatürden farklı olarak tasarruf ile enflasyon arasındaki ilişkiyi modele başka hiçbir makroekonomik değişken katmadan ölçmek esas alınmıştır.

\section{ARDL Sınır Testi Yaklaşımı}

Bu çalışmada ARDL sınır testi uygulanmaktadır. Literatürde de sıklıkla karşılaşılan bu analiz yönetim ile ilgili birkaç örnek aşağıda özetlenmektedir. Pata $(2018$, s. 92) çalışmasında tasarruf, enflasyon ve büyüme değişkenleri ile ARDL analizi yapılmış ve değişkenler arasındaki nedensellik ilişkisi tespit edilmiştir. Çağlayan (2006, s. 423) çalışmasında enflasyon, büyüme ve faiz oranı değişkenlerinin tasarruflar üzerindeki etkisini ARDL test ile analiz etmektedir. Yukarıda analiz yöntemi için örnek gösterilen çalışmalarda tasarruf-enflasyon ikilisine ek olarak modellerde büyüme ve faiz değişkenleri dahil edilmiştir. Çalışmada literatürden farklılaşmamızı sağlayan aşama burada başlamaktadır. Literatürde ARDL analizi ile sadece tasarruf-enflasyon ikilisini doğrudan ele alan güncel bir çalışma görülmemiştir.

Bu çalışmada Türkiye' de tasarruf ve enflasyonun eş bütünleşik olup olmadığ 1 incelemek üzere 1974-2017 Dönemi'ne ait tasarruf(x600) ve enflasyon(x679) değişkenleri ampirik bir analize tabi tutulmuştur. Veriler tamamı (WDI) Dünya Bankası'dan elde edilmiştir. 


$$
\Delta x 600_{t}=\beta_{0}+\sum_{i=1}^{p} \beta_{i} \Delta x 600_{t-i}+\sum_{i=0}^{q} \alpha_{i} \Delta x 679_{t-i}+\theta_{0} x 600_{t-1}+\theta_{1} x 679_{t-1}+\varepsilon_{t} \text { (1) }
$$

Burada enflasyon(x679) serisi Türkiye'nin 1974-2017 yılları için enflasyon değerleri, tasarruf(x600) serisi Türkiye'de 1974-2017 tasarruf değerlerini göstermektedir. Eşitliğin sağ tarafında yer alan ve katsayıları seriler arasındaki uzun dönem ilişkisini gösterirken ve katsayıları seriler arasındaki kısa dönem ilişkisini vermektedir. Yine tahmin edileceği üzere birinci dereceden fark operatörü, modelin sabit terimi ve modelin beyaz gürültü hata terimi olarak isimlendirilir.

ARDL sınır testi yaklaşımı ile seriler arasındaki kısa ve uzun dönemli dinamik ilişkilerin incelenmesi birkaç aşamayla gerçekleştirilir. Birinci aşamada yukarıdaki Model 1 tahmin edilir ve seriler arasında bir uzun dönem ilişkisinin var olup-olmadığına, gecikmeli serilerin katsayılarının tümünün aynı anda sıfıra eşit olduğunu iddia eden H0 hipotezinin F testi ile sınanması sonrasında karar verilir. Söz konusu F testi yardımıyla (yani seriler arasında uzun dönem ilişkisi veya eş-bütünleşme yoktur) sıfır hipotezine karşılık (yani seriler arasında uzun dönem ilişkisi veya eş-bütünleşme vardır) alternatif hipotezi sınanır. Elde edilen F istatistik değeri Pesaran vd. (2001) tarafından belirlenen üst ve alt sınır değerleri ile karşılaştırılarak karar verilir. Eğer hesaplanan F-istatistik değeri tablo alt sınır değerinden küçükse H0 hipotezi kabul edilir, eğer F-istatistik değeri tablo üst sınır değerinden büyükse H1 hipotezi kabul edilir ve F-istatistik değerinin alt ve üst sınır değerleri arasında kaldığı durumda ise karar verilemez.

Son aşamada ise aşağıda oluşturulmuş 2 no'lu hata düzeltme modeli yukarıda belirlenen en uygun gecikme sayıları kullanılarak tahmin edilir.

$\mathrm{x} 600_{\mathrm{t}}=\beta_{0}+\sum_{\mathrm{i}=1}^{\mathrm{p}} \beta_{\mathrm{i}} \Delta \mathrm{x} 600_{\mathrm{t}-\mathrm{i}}+\sum_{\mathrm{i}=0}^{\mathrm{q}} \alpha_{\mathrm{i}} \Delta \mathrm{x} 679_{\mathrm{t}-\mathrm{i}}+{ }^{\varphi} \mathrm{ECM}_{\mathrm{t}-1}+\varepsilon_{\mathrm{t}}$

Burada $\beta$ i ve $\alpha$ i modeli dengeye getiren kısa döneme ait dinamik katsayıları, ECM hata düzeltme terimini, kısa dönemdeki bir şok sonucunda modelin tekrar uzun dönem dengesine dönme ve ayarlanma hızını temsil etmektedir.

Çalışmamızda ayrıca seriler arasındaki nedensellik ilişkisinin varlığını ve yönünü belirlemek amacıyla Toda-Yamamoto yaklaşımı ile Granger nedensellik testi yapılmıştır. TodaYamamoto yaklaşımına göre önce modelde yer alan serilerin maksimum bütünleşme dereceleri (dmax) tespit edilir. Daha sonra serilerin düzey değerleri kullanılarak kısıtsız VAR modeli oluşturulup bu oluşturulan modele ilişkin en uygun gecikme uzunluğu model seçim kriterleri kullanılarak belirlenir. En uygun modelin VAR(P) olarak belirlendiği varsayımıyla daha sonra VAR ( $\mathrm{P}+\mathrm{dmax})$ modeli tahmin edilerek bu tahmin edilmiş olunan model için VAR Granger nedensellik/blok dişsallık testi uygulanır. Söz konusu VAR Granger nedensellik/blok dışsallık testi sonuçlarına göre de hangi seriler arasında ve ne yönde nedensellik ilişkilerinin var olduğuna karar verilir.

\section{Analiz Sonuçları}

Serilerin durağanlık incelemesi, H0: Seriler durağan değildir sıfır hipotezini sınayan (Augmented Dickey-Fuller Test) ADF birim kök testi kullanılarak araştırılmıştır. Görüleceği üzere serilerin düzey değerleri için yapılan ADF birim kök testi sonuçları Tablo 1'de ve serilerin birinci farkları için yapılan ADF birim kök testi sonuçları ise Tablo 2'de raporlanmıştır. 
Tablo 1. ADF testi sonuçları (düzeylerde) (sabitli model)

\begin{tabular}{|lllll|}
\hline & ADF-Stat. & $\mathbf{1 \%}$ & $\mathbf{5 \%}$ & $\mathbf{1 0} \%$ \\
\hline Log tasarruf(logx600) & -2.589072 & -4.186481 & -3.518090 & -3.189732 \\
enflasyon(x679) & -2.600544 & -4.161144 & -3.506374 & -3.183002 \\
\hline
\end{tabular}

Tablo 2. ADF testi sonuçları (I. farklarda) (sabitli model)

\begin{tabular}{|lllll|}
\hline & ADF-Stat. & $\mathbf{1 \%}$ & $\mathbf{5 \%}$ & $\mathbf{1 0 \%}$ \\
Log tasarruf(logx600) & -8.369171 & -4.192337 & -3.520787 & -3.191277 \\
enflasyon(x679) & -6.635673 & -4.170583 & -3.510740 & -3.185512 \\
\hline
\end{tabular}

ADF birim kök testi sonuçlarında görüleceği üzere Log tasarruf(logx600) ve enflasyon(x679) serilerinin I(1) (yani birinci farklarında durağan) olduğu saptanmıştır. Mevcut serilerden hiçbiri iki ve daha üst dereceden bütünleşik olmadıkları için bu serilere ARDL sınır testi yaklaşımını uygulayarak eş-bütünleşmenin var olup-olmadığını sınayabiliriz. Ayrıca Tablo 3'te Schwarz BIC kirterine göre en uygun modelin BIC= -0.097612 değeriyle ARDL $(1,3)$ nin olduğu görülmektedir. 
Tablo 3. BIC Kriterine Göre En Uygun 20 Model

Model Selection Criteria Table

Dependent Variable: LOGX600

Date: 02/16/19 Time: 21:46

Sample: 19692018

Included observations: 43

\begin{tabular}{|c|c|c|c|c|c|c|}
\hline Model & $\log L$ & AIC & $\mathrm{BIC}^{*}$ & $\mathrm{HQ}$ & Adj. R-sq & Specification \\
\hline & & & & & & \\
\hline 17 & 14.863314 & -0.393166 & $\begin{array}{l}* * * *- \\
0.097612\end{array}$ & -0.286303 & 0.957886 & $\operatorname{ARDL}(1,3)$ \\
\hline 20 & 8.457294 & -0.222865 & -0.053977 & -0.161800 & 0.946821 & $\operatorname{ARDL}(1,0)$ \\
\hline 19 & 9.526427 & -0.226321 & -0.015211 & -0.149991 & 0.948148 & $\operatorname{ARDL}(1,1)$ \\
\hline 12 & 15.033003 & -0.351650 & -0.013874 & -0.229521 & 0.956937 & $\operatorname{ARDL}(2,3)$ \\
\hline 16 & 15.004090 & -0.350205 & -0.012429 & -0.228075 & 0.956874 & $\operatorname{ARDL}(1,4)$ \\
\hline 15 & 9.038993 & -0.201950 & 0.009160 & -0.125619 & 0.946869 & $\operatorname{ARDL}(2,0)$ \\
\hline 18 & 10.565798 & -0.228290 & 0.025042 & -0.136693 & 0.949326 & $\operatorname{ARDL}(1,2)$ \\
\hline 2 & 17.708683 & -0.385434 & 0.036786 & -0.232773 & 0.959818 & $\operatorname{ARDL}(4,3)$ \\
\hline 7 & 15.597736 & -0.329887 & 0.050111 & -0.192492 & 0.956785 & $\operatorname{ARDL}(3,3)$ \\
\hline 14 & 9.788180 & -0.189409 & 0.063923 & -0.097812 & 0.947317 & $\operatorname{ARDL}(2,1)$ \\
\hline 11 & 15.180969 & -0.309048 & 0.070949 & -0.171653 & 0.955875 & $\operatorname{ARDL}(2,4)$ \\
\hline 10 & 9.225673 & -0.161284 & 0.092048 & -0.069687 & 0.945815 & $\operatorname{ARDL}(3,0)$ \\
\hline 13 & 10.876783 & -0.193839 & 0.101715 & -0.086976 & 0.948596 & $\operatorname{ARDL}(2,2)$ \\
\hline 1 & 17.849267 & -0.342463 & 0.121978 & -0.174536 & 0.958723 & $\operatorname{ARDL}(4,4)$ \\
\hline 6 & 15.725724 & -0.286286 & 0.135934 & -0.133625 & 0.955630 & $\operatorname{ARDL}(3,4)$ \\
\hline 9 & 10.066665 & -0.153333 & 0.142221 & -0.046470 & 0.946471 & $\operatorname{ARDL}(3,1)$ \\
\hline 8 & 11.539854 & -0.176993 & 0.160783 & -0.054864 & 0.948719 & $\operatorname{ARDL}(3,2)$ \\
\hline 5 & 9.663729 & -0.133186 & 0.162367 & -0.026323 & 0.945382 & $\operatorname{ARDL}(4,0)$ \\
\hline 4 & 10.441259 & -0.122063 & 0.215713 & 0.000066 & 0.945823 & $\operatorname{ARDL}(4,1)$ \\
\hline 3 & 12.148139 & -0.157407 & 0.222591 & -0.020012 & 0.948650 & $\operatorname{ARDL}(4,2)$ \\
\hline
\end{tabular}


Tasarruf(x600) serisi ile enflasyon(x679) serisi arasında eş-bütünleşmenin varlığını araştırmak için yapılan sınır testi sonuçları Tablo 4'te gösterilmektedir. Buna göre, F-istatik $=5.420013$ değeri tüm anlamlılık düzeyleri için belirlenen üst-sınır değerlerinden büyük olduğundan dolayı H0 red edilip H1 hipotezi kabul edilmektedir. Sonuç olarak Türkiye örnekleminde enflasyon ile tasarruf arasında eş-bütünleşme (uzun dönemli) ilişkisi mevcuttur.

Tablo 4. ARDL Sınır testi Sonuçları

\begin{tabular}{|lll|}
\hline Hesaplanan F istatistiği: 6.778953 & $\underline{\text { Kritik Dĕ̆erler }}$ & \\
Anlamlılık Düzeyleri & Alt-Sınır I(0) & Üst-Sınır I(1) \\
$10 \%$ & 4.05 & 4.49 \\
$5 \%$ & 4.68 & 5.15 \\
$2.5 \%$ & 5.3 & 5.83 \\
$1 \%$ & 6.1 & 6.73 \\
\hline
\end{tabular}

Aşağıda Tablo-5' de yer alan modelin uzun dönem katsayıları ve Tablo 6'da yer alan Hata düzeltme teriminin katsayısı(modelin uzun dönem dengesine dönme hızını gösterir) beklenen negatif işareti almakta ve istatistiksel olarak anlamlıdır. Enflasyon ile tasarruf arasında hem kısa dönemde hem de uzun dönemde istatistiksel olarak anlamlı bir ilişki olduğu tespit edilmiştir. Kısa dönemde enflasyondaki artış tasarrufu arttırıyor iken uzun dönemde enflasyonda meydana gelecek 1 birimlik bir artış tasarrufu -0.0077 birim azaltmaktadır.

Tablo 5. ARDL $(1,3)$ modeli uzun dönem katsayıları

\begin{tabular}{|lllll|}
\hline & \multicolumn{4}{l|}{ Bağımlı Değişken: logtasarruf(Logx600) } \\
Loğımlı Değişken: & & & \\
Enflasyonon(log679) & Katsayı & Std. Hata & t-istatistik & P-değeri \\
@TREND & -0.007757 & 0.001959 & -3.959910 & 0.0003 \\
\hline
\end{tabular}

Tablo 6. ARDL(1,3) modelinin hata düzeltmeli tahmini

\begin{tabular}{|lllll|}
\hline & \multicolumn{4}{l}{ Bağımlı Değişken: logtasarruf(Logx600) } \\
& Katsayı & Std. Hata & t-istatistik & P-değeri \\
$\Delta$ (enflasyon) & 0.000657 & 0.001289 & 0.509654 & 0.6134 \\
$\Delta$ (enflasyon(-1)) & 0.003822 & 0.001355 & 2.821190 & 0.0077 \\
$\Delta$ (enflasyon(-2)) & 0.004161 & 0.001319 & 3.154952 & 0.0032 \\
C & 12.823152 & 2.752696 & 4.658397 & 0.0000 \\
ECM(-1) & -0.548758 & 0.118440 & -4.633215 & 0.0000 \\
\hline
\end{tabular}

Seriler arasındaki nedensellik ilişkisini belirlemek amacıyla Toda Yamamoto yaklaşımı ile Granger nedensellik testi uyguland. Logtasarruf(logx600) ile enflasyon(x679) arasinda oluşturulan 1 gecikmeli kısıtlanmamış VAR modeline ait Schwarz (SIC) bilgi kriter değeri olarak 9.028054 elde edilmiş iken 2 gecikmeli kısıtlanmamış VAR modeline ait SIC değeri 
olarak 9.295158 elde dilmiştir. Bundan dolayı ilgili VAR modeli için en uygun gecikmenin 1 (yani $\mathrm{p}=1$ ) olduğu görülmüştür. Logtasarruf(logx600) ile enflasyon(x679) serileri arasında tespit edilen en yüksek bütünleşme derecesinin 1 (yani dmax=1) olduğu görülmüştü. Bundan dolayı en uygun gecikme sayısı ile en yüksek bütünleşme derecesinin toplamı olan 2 gecikme için kısıtlanmamış VAR(2) modeli tahmin edilip nedensellik testi yapılmış olup sonuçları aşağıdadır. Tablo 7'de verilen test sonuçlarına göre \%10 anlamlılık düzeyinde tasarruftan enflasyona doğru tek yönlü bir nedensellik ilişkisi olduğu tespit edilmiştir.

Tablo 7. Granger nedensellik/blok dişsallık testi

\begin{tabular}{|c|c|c|c|}
\hline \multicolumn{4}{|c|}{ Bağımlı Değişken: logtasarruf(Logx600) } \\
\hline Dişlanan & Ki-Kare & Serbestlik Derecesi & Prob.-değeri \\
\hline Enflasyon(x679) & 0.941183 & 2 & 0.6246 \\
\hline Tümü & 0.941183 & 2 & 0.6246 \\
\hline \multicolumn{4}{|c|}{ Bağımlı Değişken: Enflasyon(x679) } \\
\hline Dişlanan & Ki-Kare & Serbestlik Derecesi & Prob.-değeri \\
\hline logtasarruf(Logx600) & 5.884663 & 2 & 0.0527 \\
\hline Tümü & 5.884663 & 2 & 0.0527 \\
\hline
\end{tabular}

\section{Sonuç}

Tasarruf ve enflasyon her dönemde birbirini bir şekilde etkileyen iki makroekonomik değişkendir. Öngörüler ve literatürde karşılaşılan çalışmalar neticesinde hem kısa hem de uzun dönemli nedensellik ilişkileri göze çarpmaktadır. Bu ilişkiler ülkelere ve dönemlere göre farklı boyutta etkilere sahip olsalar dahi bir şekilde etkileşim içinde oldukları aşikârdır. Literatürde bu makroekonomik değişkenleri ele alan çoğu ampirik çalışma ARDL testinden faydalanılmaktadır. Böylelikle değişkenler arasındaki nedensellik ilişkisi incelenebilmektedir.

Çalışmada tasarruf ve enflasyon arasındaki ilişki Türkiye Örneği üzerinde ele alınmıştır. Ele alınan iki seri için durağanlıkları analizler ile incelenmiştir. Yapılan analizler sonucunda serilerin her ikiside I(1) de yani birinci farklarında durağan oldukları tespit edilmiştir. Daha sonra yapılan analizlerde ise kısa ve uzun dönemli ilişkiler ele alınmıştır. Elde edilen sonuçlara göre tasarruf ile enflasyon arasında hem kısa dönemde hem de uzun dönemde istatistiksel olarak anlamlı bir ilişki vardır. Kısa dönemde enflasyondaki artış tasarrufu arttırıyor iken uzun dönemde enflasyonda meydana gelecek bir artış tasarrufu azaltmaktadır. Seriler arasındaki nedensellik ilişkisini belirlemek amacıyla Toda Yamamoto yaklaşımı ile Granger nedensellik testi sonucunda iki seri arasında $\% 10$ anlamlılık düzeyinde tasarruftan enflasyona doğru tek yönlü bir nedensellik ilişkisi olduğu tespit edilmiştir.

Sonuç olarak bu iki değişken ülkeler ve dönemler için farklı boyutta etkilere sahip olabilmektedir. Bizim incelediğimiz 1974-2017 yılları Türkiye dönemi için tasarruf ve enflasyon analizinde uzun dönemde de tasarrufu arttıracak başka kaynaklarla desteklemek doğru olacaktır. Kısa dönemde ise enflasyonun arttırıcı etkisi zaten tasarrufu da arttırarak olumlu yönde etkilemektedir. Eşik enflasyonun olmaması, politika yapıcıların enflasyona karşı daha az hoşgörülü olmaları gerektiği anlamına gelmektedir. Daha yüksek bir enflasyon oranından kaynaklanan gönüllü bir çözülmenin, her zaman enflasyonun gelirin yeniden dağıtımı yoluyla tasarruf üzerindeki olumlu etkisini domine ettiğini görüyoruz. Bu nedenle, politika yapıcılar enflasyonu kontrol etmeye odaklanmalı ve bu da iç tasarrufu artıracaktır. 


\section{Kaynakça}

Agarwal, J. D., \& Agarwal, A. (2005). Inflation, savings \& financial Development. Finance India, 19(2), 421-448. Retrieved from https://search.proquest.com/docview/224363218?accountid=17219

Amaefule, Nwabueze Joseph \& Maku, O. Emmanuel (2019). National Domestic Savings, Inflation, Exchange Rate and Manufacturing Sector in Nigeria: ARDL Approach. EuroEconomica, 2, 314.

Ayla, Dilara ve Kızılltan, Alaattin (2018), Türkiye'de Enflasyon, Tüketim ve Tasarruf Ilişkisinin Ekonometrik Analizi. , Recep Tayyip Erdoğan Üniversitesi Sosyal Bilimler Dergisi Recep Tayyip Erdogan Universtiy Journal of Social Sciences (2018) 7: 13-41

Baiardi, D., Magnani, M., \& Menegatti, M. (2020). The theory of precautionary saving: an overview of recent developments. Review of Economics of the Household, 18(2), 513. https://doi.org/10.1007/s11150-019-09460-3

Barro, R.J. (1995), Inflation and Economic Growth. NBER Working Paper, Cambridge.

Blinov, S. (2015). Savings and Inflation Using the Example of Russia in 1992. Online at https://mpra.ub.uni-muenchen.de/67147/ MPRA Paper No. 67147

Bodie, Z. (1989). Inflation insurance (No. w3009). National Bureau of Economic Research.

Bonu, N. S.. (1995). Taxation, Inflation, Savings and Development: Case Study of Republic of Botswana. African Review of Money Finance and Banking, 1/2, 25.

Brems, H. (1979). Alternative theories of pricing, distribution, saving, and investment. The American Economic Review, 69(1), 161-165.

Browning, M., \& Lusardi, A. (1996). Household saving: Micro theories and micro facts. Journal of Economic literature, 34(4), 1797-1855.

Bruno, M.l and Easterly, W. (1998). Inflation crises and long-run growth. Journal of Monetary Economics, 41 (1), 3-26.

Bulkley, G. (1981). Personal Savings and Anticipated Inflation. The Economic Journal, 91(361), 124. https://doi.org/10.2307/2231702

Campbell, C. R., Lovati, J. M.,(1979), Inflation and Personal Saving: An Update. Federal Reserve Bank of St. Louis Review: 3-9.

Ceylan, S. (2018), Enflasyon-Özel Tasarruf İlişkisi: Türkiye Örneğgi", Anadolu İktisat ve İşletme Dergisi, 2 (1) 2018, 56-66.

Chaturvedi, V. and Dholakia, R.H. and Kumar, B. Inter-Relationship between Economic Growth, Savings and Inflation in Asia (August 8, 2008). Available at SSRN: https://ssrn.com/abstract=1212096 or http://dx.doi.org/10.2139/ssrn.1212096

Cheng, Q., \& Li, X. (2014). Cross--Country Effects of Inflation on National Savings. Econometric Analysis Undergraduate Research Papers 1-17

Cottarelli, C., Blejer, I., Mario, (1992), Forced Saving and Repressed Inflation in the Soviet Union, 198690: Some Empirical Results. IMF Staff Papers, V.9, N.2, DOI: 10.2307/3867059

Cukrowski, Jacek and Kavelashiwli, George (2002). Inflation and Adjustment of Relative Prices in Georgia. CASE-CEU Working Paper. No: 43. 
Çağlayan, E. (2006). Enflasyon, faiz oranı ve büyümenin yurtiçi tasarruflar üzerindeki etkileri.

Davidson, R., \& MacKinnon, J. G. (1983). Inflation and the savings rate. Applied Economics, 15(6), 731-743.

Deaton, A. (1983). Savings and inflation: Theory and British evidence. In The Determinants of National Saving and Wealth (pp. 125-139). Palgrave Macmillan, London.

Den Haan, W. J. (1990), The Optimal Inflation Path in a Sidrauski-type Model with Uncertainty. Journal of Monetary Economics, 25: 389-409.

Er, P. H., Tugcu, C. T., \& Coban, O. (2014). Investigating the link between savings, inflation and economic growth: an ARDL analysis for the case of Turkey. PressAcademia. Journal of Economics, Finance and Accounting - (JEFA), ISSN: 2148-6697

Er, P. H., Tuğcu, C. T., Coban, O. (2014), Investigating the Link between Savings, Inflation and Economic Growth: An ARDL Analysis for the Case of Turkey. Journal of Economics Finance and Accounting, 1(2): 81-90.

Erkki Koskela, \& Matti Virén. (1982). Inflation, Tight Money and Household Saving Behavior: Finnish Evidence. The Scandinavian Journal of Economics, 84(3), 483. https://doi.org/10.2307/3439430

Erkki Koskela, Matti Virén. (1984) Household saving out of different types of income revisited. Applied Economics 16:3, pages 379-396.

Ferreira, M. (2017). Savings and inflation (Doctoral dissertation).

Fisher, I. (1930). The Theory of Interest. New York: MacMillan.

Friedman, M. (1957). A Theory of the Consumption Function. Princeton: Princeton University Press.

Green, F. (1991). Institutional and other unconventional theories of saving. Journal of Economic Issues, 25(1), 93-113.

Heer, B. ( 1 ), \& Sussmuth, B. ( 2 ). (n.d.). The savings-inflation puzzle. Applied Economics Letters, 16(6), 615-617. https://doi.org/10.1080/13504850701206510

Igbatayo, S., \& Agbada, A. O. (2012). Inflation, savings and output in Nigeria: A VAR approach. Journal of emerging trends in economics and management sciences, 3(5), 447-453.

Ilyas, M., Sabir, H.M., Shehzadi, A., \& shoukat, N. (2014). Inter-relationship among Economic Growth, Savings and Inflation in Pakistan, Journal of Finance and Economics. 2014, Vol. 2, No. 4, 125-130 Available online at http://pubs.sciepub.com/jfe/2/4/4

Juster, F. Thomas \& Wachtel, Paul. (1972). A Note on Inflation and the Saving Rate. Brookings Papers on Economic Activity. 1972(3), 765. https://doi.org/10.2307/2534131

Karaçor, Zeynep (2001). İstikrar Politikaları ve Uygulamaları (1. Baskı). Konya: Dizgi Ofset Matbaacilik.

Keynes, J. M. (1936). The General Theory of Employment, Interest and Money. London: MacMillan.

Koskela, Erkki \& Virén, Matti. (1992). Inflation, Capital Markets and Household Saving in the Nordic Countries. The Scandinavian Journal of Economics, 94(2), 215. https://doi.org/10.2307/3440447

Kuehlwein, M. (1993). Life-cycle and altruistic theories of saving with lifetime uncertainty. The Review of Economics and Statistics, 38-47. 
Leff N. H., Sato K. (1988), A Simultaneous Equations Model of Savings in Developing Countries. Journal of Political Economy, 83(6): 1217-1228.

Mansoorian, A., Michelis, L., \& Mohsin, M. (2010). Savings, Investment, Employment, And Inflation In A Small Open Economy With Habit Persistence. Macroeconomic Dynamics, 14(3), 365-387. doi:10.1017/S1365100509090336

Modigliani, F. ve Brumberg, R. H. (1954). Utility Analysis and The Consumption Function: An Interpretation Of Cross-Section Data. K. K. (Editör) içinde, Post-Keynesian Economics, New Jersey: Rutgers University Press.

Motley, B. (1998). Growth and Inflation: A Cross-Country Study. Economic Review-Federal Reserve Bank of San Francisco, 1, 15-28.

Mundell R. (1963). Inflation and Real Interest. Journal of Political Economy, 71: 280-83.

Pata, U. K. (2018). Türkiye'de enflasyon, tasarruf ve ekonomik büyüme arasındaki ilişkilerin simetrik ve asimetrik nedensellik testleri ile analizi. Maliye Dergisi, 174, 92-111.

Patra, S. K., Murthy, S., \& Biswal, A. Savings-Growth-Inflation nexus in Asia: Panel Data Approach. Journal of Economics and Finance. e-ISSN: 2321-5933, p-ISSN: 2321-5925.Volume 6, Issue 4. Ver. II (Jul. - Aug. 2015), PP 75-85

Pesaran, M. H. \& Evans, R. A.. (1984). Inflation, Capital Gains and U.K. Personal Savings: 1953-1981. The Economic Journal, 94(374), 237. https://doi.org/10.2307/2232346

Pigou, A. C. (1943). The Classical Stationary State. Economic Journal, 53(212), 343-351.

Premik, F., \& Stanisławska, E., (2017). The Impact of Inflation Expectations on Polish Consumers' Spending and Saving. Eastern European Economics, 55(1), 3-28. https://doi.org/10.1080/00128775.2016.1260474

Ramsey, F. P. (1928). A Mathematical Theory of Saving. The Economic Journal, 38(152), 543-559.

Richardson Kojo E., Innocent I. Savings. (2015). Inflation and Economic Growth Linkages: A ReExamination with Nigeria Data. Journal of Investment and Management. Vol. 4, No. 5, pp. 180185. doi: 10.11648/j.jim.20150405.16

Thirlwall, A. P. (1974). Inflation and the savings ratio across countries. Journal of Development Studies, 10, 154-174.

Thompson, Douglas N. \& Ottosen, Garry K. (1993). Long-Term Inflation Expectations. The Personal Saving Rate and Credit Standards. Business Economics, 28(4), 45-50.

Tobin, J. (1965), Money and Economic Growth. Econometrica, 33, 671-84.

Tylecote, A. (1981). The Causes of the Present Inflation (1th Edition). London: The Macmillan Press Ltd.

Ungern-Sternberg, V. T. (1981). Inflation and Savings: International Evidence on Inflation-Induced Income Losses. The Economic Journal, 91(364), 961. https://doi.org/10.2307/2232502

Wachtel, P. (1977), Inflation, Uncertainty, and Saving Behavior since the Mid1950s. Explorations Econ., 4: 558- 78 .

Woodfield, Alan \& McDonald, John (1978) On the relation between savings, distribution and inflation. The Journal of Development Studies, 14:3, 357-365. DOI: 10.1080/00220387808421681 